\title{
VERBAL AND NON-VERBAL SIGNS IN FACIAL WASH ADVERTISEMENTS: A SEMIOTIC ANALYSIS
}

\author{
Ria Andriani ${ }^{1}$, Desak Putu Eka Pratiwi ${ }^{2}$, I Dewa Ayu Devi Maharani Santika ${ }^{3}$ \\ 1,2,3)Mahasaraswati Denpasar University \\ riaandriani0099@gmail.com ${ }^{1}$
}

\begin{abstract}
This study involves the discovery of verbal and non-verbal signs, which also describe the meaning of verbal and non-verbal signs found in the facial wash commercial advertisements. The data were taken from three printed facial wash advertisements. The data source has been taken from the internet. This study used the semiotic hypothesis provided by Saussure (1983: 65) to find out the verbal and non-verbal signs and the theoretical meaning provided by Barthes (1977) to find out the meaning of verbal and non-verbal signs in the facial wash ads. The analysis used a descriptive qualitative approach to analyze the results. As a result, the three facial wash ads show verbal and nonverbal signs that enable the company to market its product. In the verbal signs of the advertising, most of them contain denotative meaning and non-verbal signs which is in part, contain connotative meaning in certain advertisements. Two advertisements used a female as a model; one advertisement used a male as a model. This means that advertisers seek to gain public attention through the use of pretty females, popular figures and natural extracts or ingredients.
\end{abstract}

Keywords: verbal signs, non-verbal signs, semiotic, facial wash advertisements

\section{Introduction}

Language is a symbolic device that is meaningful and articulates sounds (produced by these tools) that are subjective and traditional, that is used as a communication tool by a community of people to communicate their feelings and thoughts. Semantics is one of linguistics branches that deals with language and how we perceive its meaning. According to Kreidler (1998: 3), linguistic semantics is an analysis of the structure and expression of the meaning of languages. It means that, in a linguistic semantic context, it is important for us to be able to restrict ourselves to the expression of meaning in a single language. Value is often derived from a symbol as a linguistic form. The branch of semantics that discuss about this is semiotic.
Semiotics is a study of signs, symbols, particularly when they express spoken and unspeakable things. According to Saussure (1983) the sign is specified as the signifier and signified of the sign. The signifier is the type that the sign takes. Signified is a verbal and non-verbal concept. Visual signs are used for communicating using spoken or written words. It includes traditional linguistic markers such as words, phrases and sentences that tell us ideas or emotions to others. In ads, the word or slogan of the advertisement itself is the verbal sign.

People used to use non-verbal signs until they have verbal signs. The body language or expression used to communicate is a kind of non-verbal signs and a way to convey meaning without saying a word. 
In general, the advertisement is used to sell a commodity by the companies or producers. Advertisements are mainly designed to promote a good or service to the market in order to facilitate purchases. Advertisements can be really attractive that make consumers interested, trust and eager to purchase their products. Dyer (1982: 120) also noted that certain commercials use particular colour as an empirical correlation where the colour of the product, the pack of cigarettes, different cosmetics, etc. have implicit meaning.

Nowadays people purchase or buy these products because of the attractive symbols seen in the advertisements, so the company should have a technique to market its products by creating advertisements.

The facial wash advertisements are used as a data source because it is really interesting and challenging to find out the implicit meaning of verbal and non-verbal signs used in those advertisements.

\section{Research Method}

The data were taken from three printed commercial facial wash advertisements. The data were obtained using the observation method by closely reading the printed commercial facial wash advertisements. The data were categorized into verbal and non-verbal signs. Data then analyzed quantitatively using certain theories, such as theory of semiotic from Saussure (1983: 65) to identify signifier and signified; theory from Barthes (1977) to analyse the meaning of the signs; and supporting theory from Wierzbicka (1996) to analyse the color terms. The data were presented in formal and informal method.

\section{Discussion}

Facial Wash Advertisements consists of verbal and non-verbal signs. Verbal signs consist of words and sentences. While, non-verbal signs consist of model or figure that combines with the picture of the product and color. The analysis of verbal and nonverbal signs can be seen in the following section.

\subsection{The Analysis of Clean \& Clear Facial Wash Advertisement}

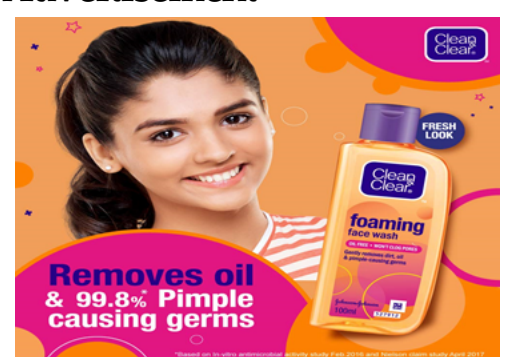

Figure 3.1 Clean \& Clear Facial Wash Advertisement

\subsubsection{The Analysis of Verbal Signs}

There are verbal signs seen in the advertisement above. The first one is "Clean \& Clear." This statement dearly explains that advertisers want to catch the attention of the audience by using a company name that is well known in society. This product is recommended for those who want to control oil and remove 99.8\% of the germ-causing pimple from their skin, which is also suitable for all skin types. This oil - free formula cleans thoroughly to remove excess oil and dirt without drying out too much with antibacterial ingredients to help prevent acne breakout. It has connotative meaning because it gives the product information to the brand.

The second statement is 'Fresh Look.' This means that this product can give customers a fresh look after they used the product. It has connotative meaning 
because it tells customers about the benefits of using that product.

The third statement is "Oil Free, won't clog pores." This statement means this face wash would make our face free of oil. Also, this product is not clogging pores from our face, the build-up of oil can affect the appearance of the pimple on your face. It has connotative meaning because it provides information that clean and clear face wash can prevent clogging of pores.

The fourth statement is "Removes oil \& 99.8\% pimple causing germs." This statement means that when we do outdoor activity, we're going to produce more oil and dust that sticks on our face that can make us feel uncomfortable, but washing our face can make us feel fresh. This product is made for people who like to do outdoor activities to keep them feeling fresh during their activities. Even though we do outdoor activities, we will feel free from the oil and pimple that causes germs. It has connotative meaning because it tells us about the benefits of using the product, especially when having a lot of outdoor activities.

\subsubsection{The Analysis of Non-Verbal Signs}

In terms of non-verbal sign, the background of the advertisement is dominated by light colors. According to Wierzbicka (1996), light is the basic color terms learned by extension and its association. Orange and pink are dominating in the advertisement above. Orange, the blend of red and yellow, is a mixture of the energy associated with red and the happiness associated with yellow. Orange is the color of joy and creativity. Orange promotes a sense of general wellness and emotional energy that should be shared, such as compassion, passion, and warmth. Meanwhile, pink, a delicate color that means sweet, nice, cute, romantic, charming, feminine, and tenderness. Pink is the color of universal love of oneself and of others. Pink represents friendship, affection, harmony, inner peace, and approachability. These color implicitly carried the ideas stated above.

Another non-verbal signs is the model which is a beautiful woman. Women have a dominant role in attracting people's attention by their beauty and tempting smile on their faces. The beautiful model implicitly tells the people that this product makes women look gorgeous with fresh soft face skin. The model fresh look will persuade the people to buy and use the product to get the same benefit like the model.

There is also the picture of the product to show the people the packaging of the product. It gives information for people who interested to buy the product to get it easily at stores. Showing the product is very important to introduce it to public and make them familiar with the product.

\subsection{The Analysis of Garnier Men Facial Wash Advertisement}

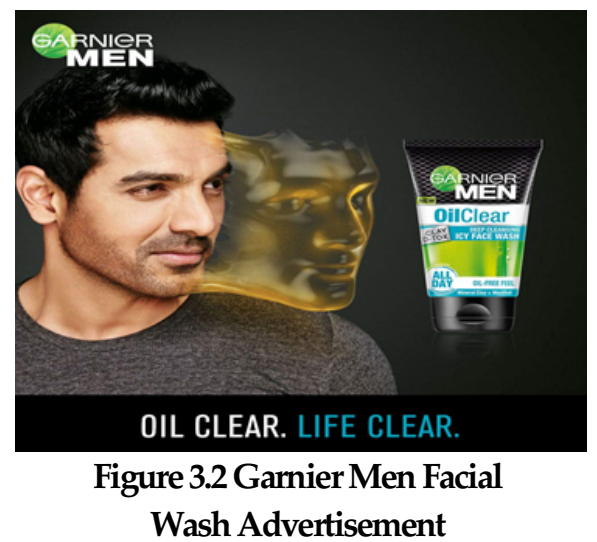

Yavana Bhāshā: Journal of English Language Education March 2021, Volume 4, Issue 1 


\subsubsection{The Analysis of Verbal Signs}

There are three verbal signs that found on the advertisement above. The first statement is "Oil clear. Life clear". This statement means that we can remove excess oil on our faces. In addition, this product reduces the build-up of oil and can make us confident in our activities. This product is recommended for men with oily skin problems. It implicitly tells the people that when they have clear face, they will also have clear life since they feel worry free and be more confident.

The second statement is "Deep cleansing icy face wash." This means that this product can make the skin clean and fresh because of its mineral clay absorbing oil. It is also enhanced with menthol \& clay that makes consumers feel fresh all the time. The cool feeling comes from menthol and clay that can make customers feel fresh and cool like ice. After using this product, customers feel relaxed and calm. It has a denotative meaning because it informs the customer about the benefit of the product.

The third statement is "Garnier Men". This statement is clearly the name of the product. It is also used to highlight that the product is specifically created for men.

\subsubsection{The Analysis of Non-Verbal Signs}

The first nonverbal sign is the background of the advertisement which is black. Black is associated with power, mystery, strength, authority, elegance, authority, rebellion, and sophistication. Black is required for all other colors to have depth and variation of hue. The color blackaffects the mind and body by helping to create an inconspicuous feeling, boosting confidence in appearance, increasing the sense of potential and possibility.

The next nonverbal sign is the model of the advertisement which is a good looking man with mysterious confident smile. There is also a picture of oil mask which lifted out of the model's face. It shows the power of the product to remove oil from the whole face skin. Having oil free skin makes everybody feel confident and good looking. It implicitly persuades people to use the product so they will have clear face and clear life.

There is also the picture of the product which is small and easy to store. Men typically love something simple and easy so that the packaging is made to fit their need. In addition, the product is designed in black and green color. Green, the color of life, renewal, nature, and energy, is associated with meanings of growth, harmony, freshness, safety, fertility, and environment. The color green has healing power and is understood to be the most restful and relaxing color for the human eye to view.

\subsection{The Analysis of Cetaphil Facial Wash Advertisement}

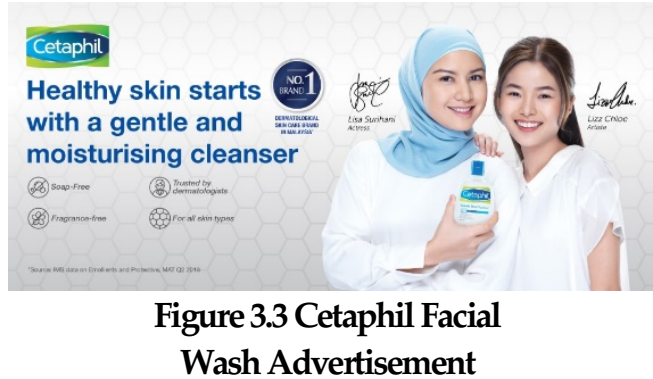

\subsubsection{The Analysis of Verbal Signs}

There are four verbal signs that found on the advertisement above. The first statement is "Healthy skin starts with a gentle and moisturizing cleanser". Many people, especially women are worried 
about their faces, such as dry skin, which may cause premature aging. This means that this face wash product is made to moisturize our face with the extract that occurs in the product. Without being worried about the chemical, we can do anything to our face. It has a denotative meaning because it tells the consumer about the product.

The second statement is "Soap free, fragrance free, trusted by dermatologists, for all skin types". The product formula is pure and gentle, but it effectively cleans and moisturizes the skin without any added fragrance and does not contain excessive foam so that it is soft on the skin and does not damage the natural moisture of the skin. It has been dermatologically tested, making it suitable for even sensitive skin as a cleanser. It has a denotative meaning because it tells consumers about the advantages of the product.

The third statement is "Cetaphil". Cetaphil is produced by Galderma, a dermatological company that makes a face wash product with hypoallergenic formula. Cetaphil is a solution for people with dry skin. It has a denotative meaning because it indicates the name of the product to the consumer.

The fourth statement is "Brand no.1 dermatological skin care brand in Malaysia". This statement means that a lot of people in Malaysia use this face wash product that makes it the No.1 brand because it has been dermatologically tested. The purpose of the above statement is to attract more people, especially women from all around the country, to buy and use this face wash because this product has many advantages.

\subsubsection{The Analysis of Non-Verbal Signs}

There are non-verbal signs of the cetaphil facial wash advertisement above. The background is white, girl's shirt and the packaging of the product are white and blue. It has connotative meaning. Based on Wierzbicka (1996) white color represents goodness and purity while blue color represents health and softness. The white color of the background here, the girl's shirt and the packaging of the product mean the goodness and purity of the product that can help consumers take care of their face because the product uses pure ingredients. Then the blue color here means softness, it gives a message that this product makes our skin face soft.

Meanwhile, Lisa Surihani and Lizz Chloe are known as Malaysia's famous actress. It has connotative meaning. This product keeps the user feeling fresh and reduces the wrinkles on the skin of the face. It emphasizes that the famous actress and artist used this product to keep their performance nice and avoid face skin problems while doing activities.

The other non-verbal sign in the advertisement above is Lisa Surihani's and Lizz Chloe's signatures here mean that the advertiser trying to inform consumers that Lisa Surihani and Lizz Chloe used the product by showing their signature on the advertisement. It has a denotative meaning because the signature here has been used to convince Lisa Surihani and Lizz Chloe to be the user of the product and to encourage people to use the product as well.

The picture of product is presented in the advertisement to attract the people to see it so that they can easily recognize it in stores and buy it. The packaging is very easy to carry, especially when you do 
activities outside so you can wash your face anytime and anywhere.

\section{Conclusion}

The verbal signs in the facial wash advertisements were used to provide information about the ingredients and benefits of the products. Verbal signs also play crucial role in persuading and convincing people to buy and use the products. The messages are delivered explicitly and implicitly through the texts. Most of them use declarative sentence. The important information like the name and the benefit of the products are written in bold capital letters and various attractive colors.

Meanwhile the nonverbal signs generally use particular colors, models and the picture of the products. The background of the advertisement for women product use bright colors such as orange, pink and white. Bright colors represent energy, wellness, affection, harmony, love, freshness, friendship, etc. Meanwhile the product for men used dark color which is black. It represents power, mystery, strength, authority, elegance, authority, rebellion, and sophistication. The models of the advertisements are beautiful women and a good looking man which represent the effect and the benefit of using those products which make you beautiful or handsome and be more confident. All of the advertisements also presented the picture of their product. It aims to introduce and promote the products to public so people will be familiar with the look of the products and can easily find them in stores.

\section{References:}

Amazon (n.d).Clear \& clean fresh look. Retrieved September 09, 2020 from

https://www.amazon.in/Clean-

Clear-Foaming-Face100ml/dp/B00OBEZH54

Barthes, R. 1987. Elements of Semiology. Hill and Wang, New York: A Division of Farrar, Straus and Giroux.

Dyer, G. 1982. Advertising as Communication. London: Routledge.

Garnier men face wash. Retrieved September 09, 2020 from https://menshaircare.net/garnie r-men-face-wash/

Saussure, Ferdinand de. 1983. Course in General Linguistics. (Bally, C, \&Sechehaya, A.) New York: MeGraw-Hill Book Company.

Weirzbicka, A. 1996. SEMANTICS:

Primes and Universal. New York:

Oxford University Press.

Watsons

(n.d.).Cetaphilmoisturising cleanser.Retrived September 09, 2020 from https://www.watsons.com.my/a $\underline{\text { ll-brands/b/154066/cetaphil }}$ 